\title{
Do NSAIDs prevent colorectal cancer?
}

\author{
Nadir Arber MD MBA
}

\begin{abstract}
N Arber. Do NSAIDs prevent colorectal cancer? Can J Gastroenterol 2000;14(4):299-307. There is increasing evidence to suggest that acetylsalicylic acid (ASA) and other nonsteroidal anti-inflammatory drugs (NSAIDs) reduce the risk of colorectal cancer. This observation is supported by animal studies that show fewer tumours per animal and fewer animals with tumours after administration of several different NSAIDs. Studies in humans consistently support this hypothesis. Intervention data from familial adenomatosis coli establish that the process of human colonic adenoma polyp formation is affected. Supportive evidence comes from 21 of 23 human studies - both case-control and cohort. The reduced risk has been found in men and women, for cancers of the colon and the rectum and for the use of both ASA and the other NSAIDs. Earlier detection of lesions as a result of drug-induced bleeding does not seem to account for these findings. The molecular mechanisms responsible for the chemopreventive action of this class of drugs is not completely established. Protection may affect several pathways, including cell cycle arrest and induction of apoptosis. Because of the consistency of epidemiological, clinical and experimental data, there is no need for further placebo trials. At the same time, there is a need to establish the dose, duration and frequency of use required for cancer-preventive activity.
\end{abstract}

Key Words: Acetylsalicylic acid; Colorectal cancer; Nonsteroidal anti-inflammatory drugs

\section{Les AINS préviennent-ils le cancer rectocolique?}

Les preuves s'accumulent à l'effet que l'acide acétylsalicylique (AAS) et autres anti-inflammatoires non stéroïdiens (AINS) pourraient réduire le risque de cancer rectocolique. Cette observation s'appuie sur des études animales selon lesquelles le nombre de tumeurs par animal et le nombre d'animaux portant des tumeurs diminuent après l'administration de différents AINS. Les études menées chez l'être humain ont confirmé cette hypothèse. Les données d'intervention sur l'adénomatose familiale concluent que le processus de formation des polypes d'adénomes coloniques chez l'être humain est affecté. Les preuves à cet effet proviennent de 21 études sur 23 avec cas témoins et de cohorte portant sur l'être humain. La réduction du risque a été observée chez l'homme et chez la femme dans les cas de cancer du côlon et du rectum pour l'AAS et les autres AINS. Le dépistage plus précoce des lésions par suite des saignements provoqués par les médicaments ne semble pas contribuer à ces observations. Le mécanisme moléculaire responsable de l'action chimique préventive de cette classe de médicaments n'est pas complètement élucidé. La protection pourrait passer par différentes voies y compris l'arrêt du cycle cellulaire et l'induction de l'apoptose. Compte tenu de la constance des données épidémiologiques, cliniques et expérimentales, il n'est pas nécessaire de procéder à d'autres études avec témoins sous placebo. Par contre, il sera nécessaire de confirmer la dose, la durée et la fréquence d'utilisation nécessaires pour exercer une activité préventive contre le cancer.
$T$ his review focuses primarily on the potential chemopreventive activity of nonsteroidal anti-inflammatory drugs (NSAIDs) in sporadic human colon cancer and adenomas, and outlines the current concepts of the biological and biochemical mechanisms of its action.

\section{BACKGROUND AND HISTORY}

The clinical use of salicylates dates back to Biblical times. In Egypt, the Pharaohs applied dried leaves of myrthe to ease rheumatic pain. Throughout the Old and Middle ages, from China, through the Greek period to the Roman Empire, further uses of salicylate were advocated to treat inflammation and to relieve pain. The first acetylsalicylic acid (ASA) compound was formulated a century ago, and currently over 50 billion prescriptions are written every year $(1,2)$.

It was predicted that cancer would become the leading cause of death in the United States (surpassing heart disease) by the year 2000 (3). Colorectal cancer (CRC) is a major

This mini-review was prepared from a presentation made at the World Congress of Gastroenterology, September 6 to 11, 1998, Vienna, Austria Gastrointestinal Oncology Unit, Department of Gastroenterology, Tel-Aviv Sourasky Medical Center and Sackler School of Medicine, Tel Aviv University, Israel

Correspondence: Nadir Arber, Associate Professor of Medicine, Director - GI Oncology Unit, Department of Gastroenterology, Tel-Aviv Sourasky Medical Center, 6 Weitzmann Street, Tel-Aviv 64-239, Israel. Telephone +972-3-6974968/280, fax +972-3-6974622, e-mail

narber@post.tau.ac.il,ornadir@tasmc.health.gov.il

Received for publication August 23, 1999. Accepted September 7, 1999 
health problem, comprising about $9 \%$ of all cancers worldwide, with 783,000 new cases per year (4). It is the second leading cause of cancer death in the western hemisphere, reaching a peak of 131,000 new cases and 57,000 deaths in the United States during 1994 (5). The same numbers are expected for 2000 as well, with projected CRC deaths in 27,800 men and 28,800 women (4) (unpublished data).

Morson (6) proposed the evolving concept of an adenoma-carcinoma sequence, and a group from Johns Hopkins, Baltimore, Maryland, described the molecular basis of this progression $(7,8)$. This paradigm is now well established. The strongest supportive clinical evidence is that patients who are maintained 'adenoma free' by polypectomy are generally kept 'cancer free' (9).

Because of the long latency period (a decade or more), there is increasing scientific and clinical interest in colon cancer prevention, either by impeding the adenoma formation and recurrence, or by interference with the neoplastic progression. Despite advances in medical practice and intensive research into various chemotherapeutic agents, CRC is often diagnosed at an advanced stage, when it is resistant to most therapeutic effects. Therefore, early diagnosis and prevention are approaches that are under active investigation, as is the use of chemoprevention. Chemopreventive measures are especially important in patients who are at increased risk for neoplasia caused by genetic and environmental factors. Although research on such agents is blossoming, only a few compounds have been shown to be useful in vivo (10). Among these are the family of NSAIDs.

The association between NSAIDs and CRC is intriguing and comprehensive. The following lines of evidence suggest that NSAIDs reduce the incidence and mortality from CRC.

- The NSAID class of agents has been shown to prevent carcinogen-induced CRC in rodents (reviewed in 11-15).

- Sulindac treatment induces a dramatic regression of adenomas in patients with familial adenomatous polyposis (FAP) coli (16-20).

- Human epidemiological data show that regular, long term use of ASA or other NSAIDs is associated with a decreased death rate from CRC (reviewed in 21-25).

\section{ANECDOTAL AND CASE REPORTS}

As with many important findings in medicine, observant physicians found the relationship between NSAID use and colorectal neoplasia accidentally. They noted that FAP patients receiving NSAIDs for the management of rheumatoid and other inflammatory disorders, surprisingly also experienced a regression of a variety of tumours $(16,17,26)$.

\section{ANIMAL MODELS}

Kudo et al (27) conducted the first important study. They coadministered indomethacin and a colon carcinogen to rats. The rats developed fewer colonic tumours than did the control group, suggesting a protective effect of the NSAID. Numerous animal studies (reviewed in 23,28-32) followed these pioneering experiments, in which different members of the NSAID class of drugs consistently prevented carcinogen (eg, azoxymethane, dimethlhydrazine, methylnitrosurea or methylazoxymethanol) -induced colonic carcinogenesis in rodents. NSAIDs were used in these studies because of their ability to inhibit prostaglandin (PG) synthesis, which participates in the tumourigenesis process. In most studies, concomitant administration of the carcinogen and NSAID resulted in a reduced number of animals with tumours, a decreased number of tumours per animal and smaller tumours compared with controls. The antitumoural effect appeared to work at several stages of colorectal carcinogenesis. At least part of the chemopreventive effect of the NSAIDs occurs at early stages in the process of carcinogenesis. They inhibit the formation and or growth of aberrant crypt foci, which are thought to be the earliest histologically neoplastic lesions in the carcinogen-induced models (31). Rao et al (15) showed that this effect was also noted when the drug was not given until 14 weeks after carcinogen administration, suggesting that it can induce the regression of already initiated neoplastic foci.

In recent years, studies using transgenic mice recapitulated these findings. Of special importance were studies using the multiple intestinal neoplasia (Min) mouse model. This model was developed after C57BL/6J mice were treated with a colon carcinogen and then bred for transmission of germline mutations (32-34). These mice demonstrated a phenotype similar to that of FAP in humans, and different NSAIDs were shown to inhibit adenoma formation in these animals (32-34).

Several dozen reports support the concept that NSAIDs are effective in the chemoprevention of CRC in a variety of animal models. These agents appear to act at the initiation and promotion stages of carcinogenesis with varying degrees of efficiency. Recently, preliminary data revealed that NSAIDs may have additive chemopreventive effects with other chemotherapeutic agents (unpublished data).

\section{CLINICAL TRIALS IN FAP PATIENTS}

Clinical support comes from studies with FAP patients (reviewed in 23,24,28,35), providing an excellent human model system for observing regression of adenomatous polyps. Waddell et al $(16,17,26)$ made the initial observation regarding regression of colonic adenomas in patients with FAP following sulindac treatment, and surprisingly, seven years passed before the first controlled trial confirmed that initial observation (19). Subsequently, several other controlled clinical trials in FAP patients $(20,36-38)$ also demonstrated that sulindac caused a dramatic regression of existing adenomas as well as the prevention of new adenoma formation. Approximately a dozen small prospective intervention studies were carried out in more than 50 patients $(23,24,35,39)$, and all the trials demonstrated partial or complete regression of colorectal polyps. It is important to emphasize that the effect of NSAIDs is transient and that virtually all patients had regrowth of their adenomatous polyps on termination of therapy. 


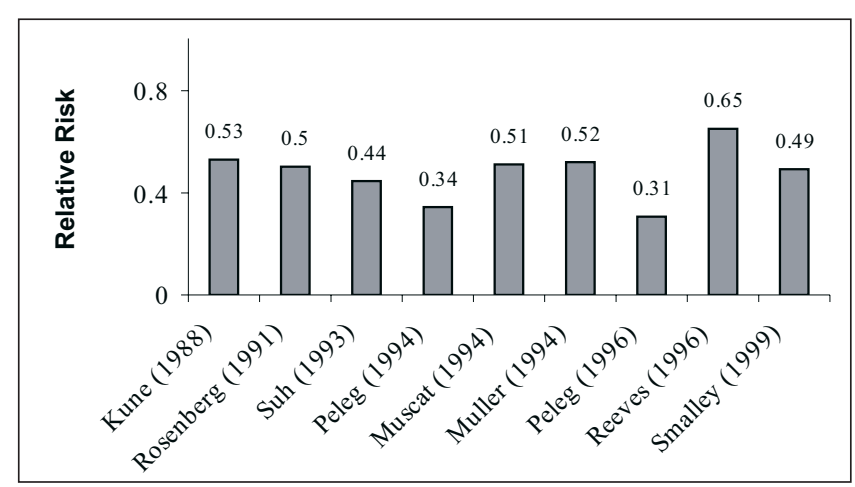

Figure 1) Summary of retrospective studies of nonsteroidal antiinflammatory drug use and colorectal cancer

The reduction in number and size of colorectal polyps was confirmed recently in two international, multicentre, randomized, placebo-controlled trials. One evaluated the effect of Aptosyn (Exisulind, sulindac sulphone, Cell Pathway Inc, Horsham, Pennsylvania) in FAP patients after subtotal colectomy. In this study, Aptosyn prevented $50 \%$ of polyp recurrence. When all placebo patients, regardless of subgroup, were crossed over to the drug, there was a 50\% reduction in the polyp formation rate within six months $(\mathrm{P}=0.005)$. All patients continuing from the drug-treated group for an additional six months showed a $58 \%$ additional reduction in their polyp formation rate $(\mathrm{P}=0.006)$. This confirms the phase III findings and confirms that the patients continue to get better without losing the drug effect out to 18 months (Arber, personal communication). In the second study, a selective cyclo-oxygenase (COX) - 2 inhibitor was used (Celecoxib, Searle-Monsanto, Skokie, Illinois) in FAP patients with intact colon. Thirty-five per cent of polyp regressions were noted in this study (Arber, personal communication).

\section{EPIDEMIOLOGICAL STUDIES}

Despite the extensive animal studies and preliminary clinical data, only during 1991 did epidemiological studies begin to examine the hypothesis that NSAIDs protect from CRC.

Overall, 21 of 23 epidemiological studies consisting of approximately 18,000 cases have shown that regular use of ASA or other NSAIDs lowers the risk of CRC by about $50 \%$ (reviewed in 21-25,39,40). The studies were undertaken in a variety of settings using CRC occurrence or mortality as the primary endpoint. The protective effect was seen in men and women of all age groups. Only one trial showed a null effect $(41,42)$, and one found a significant increase in deaths due to colon cancer among regular ASA users $(43,44)$.

\section{RETROSPECTIVE STUDIES}

Nine studies (45-53) demonstrated a protective effect of NSAIDs against CRC, although only two were designed specifically to assess the effect of NSAIDs $(47,53)$ (Figure 1). The studies were hospital-based, except for one that was community-based (46). Most studies determined NSAID exposure history in patients and controls during an interview

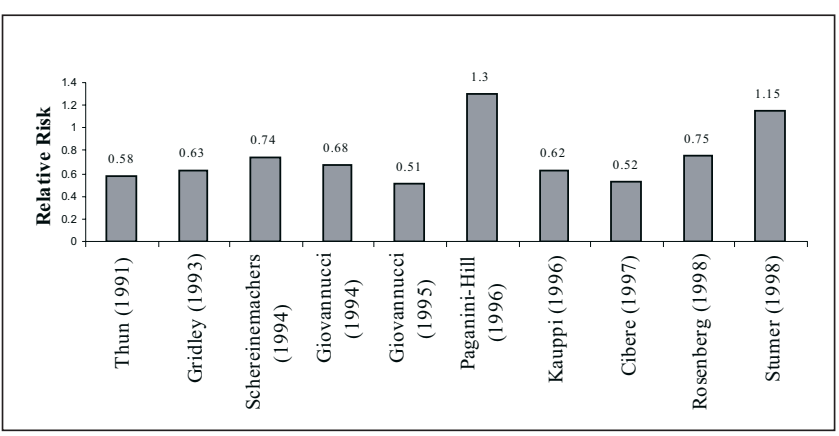

Figure 2) Summary of prospective studies of nonsteroidal antiinflammatory drug use and colorectal cancer

at entry to the study $(23,24,54)$. Two studies also examined the effect of acetaminophen, which is an important confounder, and did not find any protective effect. Similarly Peleg et al (48) did not find any protective effect for the use of steroids, calcium, multivitamins or psyllium.

The first population-based, case control study came from Australia. Kune et al (46) reported a 40\% decrease in CRC risk among 715 people who consumed ASA on a regular basis compared with 727 nonconsumer controls. In a subsequent case control study reported from the Boston area (51), the use of ASA at least four times per week was associated with a 50\% relative risk (RR) decrease for CRC.

A recent very important study performed in 104,217 elderly individuals from the Tennessee Medicaid program confirmed those results (45). The study demonstrated that long term use of NSAIDs halved the risk of CRC, confirming previous reports that the duration of use and not just the dosage is the important factor for chemoprevention. It was also clearly shown that protection is most pronounced in right sided lesions. Finally, the study is important because it is the only one that clearly demonstrates the protective effect of most NSAIDs, and was not confined to a small number of these drugs.

\section{PROSPECTIVE STUDIES}

Of the 10 studies carried out, eight demonstrated the protective effect of NSAIDs (42,44,55-62) (Figure 2), although only two were designed to assess specifically the effect of NSAIDs on colon cancer. Most studies determined NSAID exposure history in patients and controls during an interview at the entry to the study. Two studies examined the effect of acetaminophen, which is an important confounder, and were unable to find any protective effect.

The American Cancer Society performed a landmark study that has been widely cited (55), raising huge public awareness. In this study, one million people were interviewed regarding their personal health habits and cancer risks. A study of death certificates revealed that 507 individuals died of CRC from a population of over half a million who had given complete information. The RR for having CRC ranged from 0.48 to 0.68 , with a correlation to the amount of ASA consumed. The greatest reduction in mor- 


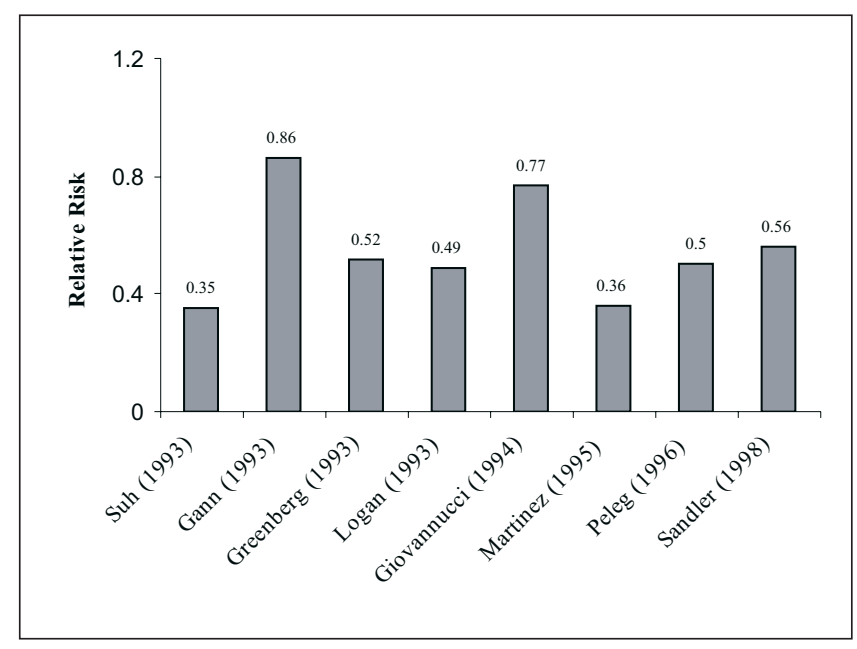

Figure 3) Summary of studies of nonsteroidal anti-inflammatory drug use and adenomatous polyps

tality was observed among people consuming more than 16 pills a month. Unfortunately, the outcome measured by this and other studies was mortality and not incidence. In addition, the issue of NSAIDs dose was not resolved.

The Male Health Professionals study (58) was initiated in 1986 by a mailed questionnaire and included 47,900 nonphysician health care workers. The data were confirmed by follow-up surveys in 1988, 1990 and 1992. A total of 251 CRC cases were identified. Following multivariate analysis, a marked decrease in CRC and adenoma risk (RR 0.35 to 0.68 ) was seen among ASA users compared with nonusers. The protective effect was dependent on the dosage and duration of consumption of these drugs.

The Nurses' Health study cohort was established in 1976 and included 121,701 female nurses who returned a mailed questionnaire every two years. In 1995, Giovannucci et al (56) reported that regular ASA use substantially reduced the risk of CRC. However, the benefit becomes evident only after 10 years of regular use of at least two tablets a week.

Rosenberg et al (57) conducted, between 1992 and 1994, a prospective population-based, case controlled study of CRC in Massachusetts, and it is one of the few studies that confirmed that ASA and other NSAIDs are equally effective. The data that were collected from 1201 patients with colorectal cancers and 1201 matched controls revealed that regular ASA or NSAID use, until one year before the diagnosis, was associated with a significant reduction, of $30 \%$ to $40 \%$, in CRC incidence. Three additional, prospective studies (59-61) showed similar results with a clear protective effect of NSAID use.

On the other hand, two studies demonstrated conflicting results. The first, designed to study osteoporosis in 14,000 elderly residents of Southern California, contradicted the findings mentioned above. Surprisingly, daily users of ASA were found to have an RR for CRC of $1.5(43,44)$. Three years later, in a subsequent follow-up report on the same retirement community, there was again no protective effect and an RR of colon cancer of 1.5 in men and 1.0 in women
$(41,42)$. This study differed from most other epidemiological surveys in several aspects - the subjects were quite elderly (median age of 73 years) and many of them were health conscious. Additionally, there may have been a bias in ascertaining ASA use because the data were based on a single questionnaire session held before entry to the study; therefore, nonusers might have became users at a later stage.

The Physicians Health Study (PHS) (41) was a large intervention trial to prevent cardiovascular mortality. It was a well designed, double-blind trial in which 22,071 American physicians were randomly assigned to four groups - placebo, placebo and ASA (325 mg ASA every other day), placebo and beta-carotene, and beta-carotene and ASA. Four years later, the study was halted unexpectedly because of the clear cardiovascular protection that was observed for ASA. A lower RR of 0.86 for polyps and a higher RR of 1.15 for CRC were noted. A total of $33 \mathrm{CRC}$ cases hampered statistical analysis, and the difference was not statistically significant. The ASA intervention in the PHS was fairly short term and of a low dose because its primary endpoint was cardiovascular mortality and not tumour protection. It is quite possible, therefore, that this study overlooked a genuine effect. However, while the duration of the follow-up increased to 12 years, there was still no protective effect for ASA consumers (42).

Most studies have not generated sufficient data to study carefully the relationship between dose and duration of ASA use and CRC risk. This was evaluated only by the American Cancer Society study (55), the Nurses Health Study (56) and the study by Smalley et al (45), and suggested that a relatively low dose of three to four tablets per week is adequate. The Nurses Health Study (56) also clearly showed a strong correlation between duration of ASA use and CRC risk; no risk reduction was observed until after more than 10 years of ASA use. Few of the epidemiological studies have had enough data on the use of NSAIDs other than ASA to arrive at any conclusions. Those who had this information usually found an effect similar to the one seen with ASA use $(45,57)$.

\section{COLORECTAL ADENOMATOUS POLYPS}

The adenomatous polyp is the premalignant precursor lesion for CRC (7-9). There is strong clinical evidence that patients who are maintained adenoma-free are generally kept cancer-free. Furthermore, the lower incidence of CRC after adenoma removal, as shown in the National Polyp Study, supports this theory (9).

Compared with FAP studies, intervention trials in sporadic colonic adenomas are more difficult to perform. The preventive effect, in sporadic cases, if present, is much less dramatic than that reported in subjects with FAP. It remains to be seen whether this is due to the greater difficulty in conducting the trials or whether there exists a fundamental difference in the process of colonic carcinogenesis in these two settings.

Several trials found a reduced risk of colorectal adenomatous polyps (CRP) among NSAID users $(41,48,50,58,63-67)$ 
(Figure 3). A case controlled study from Buffalo, New York analyzed 212 incident cases of CRP (without any histological classification) and found the RR for CRP in ASA users to be 0.35 (50). Logan et al (66), in a case controlled study of fecal occult blood screening for CRC in the United Kingdom, found 147 new cases of CRP in the group with positive fecal occult blood tests -176 controls with a positive fecal occult blood test but without CRP, as well as 153 controls with negative fecal occult blood test and no polyps. The RR for adenoma was 0.6 in the ASA users compared with both control groups.

Sandler et al (65) evaluated the effect of ASA and NSAIDs in a colonoscopy-based case controlled study of 210 patients with and 169 patients without an adenoma. After adjusting for potential confounders, ASA users were about $50 \%$ less likely to develop adenomas, and the protective effects lasted at least one year after the discontinuation of the drug treatment.

Three similar NSAID polyp regression studies have been completed (68-70, reviewed in 71). Eligible subjects with small polyps in the left colon were enrolled. Polyps were identified, described, measured, tattooed and left in place. Subjects were then treated with an NSAID or, in the case of a controlled trial, placebo. The randomized, placebo controlled study done by Landenheim et al (68) reported no dramatic effect in reducing the number or size of polyps following four months of sulindac therapy. Another smaller uncontrolled trial demonstrated similar results (69). However, these studies examined only a few patients with adenomas and were, therefore, lacking statistical power. These studies lent support to the hypothesis that NSAIDs function at an early stage in the multistep process of gastrointestinal tumourigenesis. It was also suggested that NSAIDs are more effective in causing the regression of right sided than left sided adenomas (69).

A large, international, multicentre, placebo controlled trial evaluating the effect of Exsulind (Cell Pathway Inc, Horsham, Pennsylvania) in the regression of sporadic CRP has been completed. The study code is still not broken; however, polyp regression was noted in some patients (Arber, unpublished data).

\section{POTENTIAL BIASES}

The more recent descriptive epidemiological studies have tried to look for potential confounding variables that might explain the association between NSAIDs and tumour reduction. The first is that the use of NSAIDs results in an increase in gastrointestinal bleeding, which triggers a tumour workup. This may explain the reduction in tumours at an advanced stage, but does not account for the prevention of adenomatous polyps, as has been shown to occur in animal models, or the regression of polyps in FAP patients $(24,39,51,54,58)$. The second hypothetical bias might be that NSAIDs users are more health conscious and motivated. This has been addressed and excluded by multivariate analysis in several studies and would not account for the prevention of CRC seen in animal models $(24,39,51,54,58)$.

\section{THE PUTATIVE CHEMOPREVENTION MECHANISM OF NSAIDS}

The biochemical plausibility whereby NSAIDs protect against CRC comes from insight into the putative underlying mechanism, although the mechanism is not completely elucidated (reviewed in 71-80). These effects may be clinically relevant because they occur at concentrations of NSAIDs that might be reached in colon tissue in vivo (81).

NSAID protection from CRC may be directed through several pathways, including inhibition of proliferation, induction of apoptosis, prevention of procarcinogen activation and augmentation of the immune response.

The origin of this hypothesis can be traced back to 1975 $(73,80)$, when it was observed that certain human cancers and experimental animals contain more $\mathrm{PGE}_{2}$ than in the surrounding normal mucosa - an observation that has since been confirmed by many other groups (reviewed in 24,7880 ), who hypothesized that tumours overproducing $\mathrm{PGE}_{2}$ might promote their own growth and spread. PGs are mainly produced by the COX enzymes $(21,80,82-86)$, which are also called PGH synthases. Hence, it is logical to believe that inhibition of PG synthesis by NSAIDs is an important target along the pathway leading to the prevention of tumourigenesis. There are at least two isoforms of the COX protein. COX-1 is found in the normal gastrointestinal mucosa and is usually constitutively expressed. Inhibition of COX-1 in gastroduodenal mucosa by NSAIDs is generally believed to be the cause of NSAID-induced ulcers. COX-2 is not usually detectable in the normal gastrointestinal mucosa, but its expression is induced by growth factors involved in inflammatory and neoplastic processes (21,82-88).

It is well established that NSAIDs can be grouped into three groups based on their binding kinetics with the COX enzyme (21,80,82-86). Class I compounds compete reversibly with arachindonic acid (AA) for binding to the COX active site. Class II compounds are competitive, timedependent and reversible inhibitors. ASA, the prototype of class III inhibitors, works differently because it acetylates the enzyme and thereby irreversibly inactivates COX.

The COX enzyme has two distinct catalytic activities at two separate sites. It cyclizes and oxygenates $\mathrm{AA}$ to $\mathrm{PGG}_{2}$, and it also has peroxidase activity reducing $\mathrm{PGG}_{2}$ to $\mathrm{PGH}_{2}$. COX levels increase in colon tumours $(21,83-88)$, and inhibition of COX enzymes diverts the AA cascade into lipoxygenase metabolites. NSAIDs may also directly influence cell proliferation in the colonic mucosa $(21,82)$, at least in part by downregulating cyclin D1 expression (89) or cyclindependent kinase activity $\left(\mathrm{CDK}_{4}\right)(89)$, or increasing the level of $p 21^{\text {waf1 }}(90,91)$. NSAIDs also inhibit DNA synthesis, cell cycle progression, synthesis of growth factors and the incorporation of ${ }^{3}(\mathrm{H})$-thymidine into cellular DNA in cell culture models (72,74-76,90-92).

An alternative PG-based theory suggests that inhibition of COX prevents the formation of free radicals, which can damage cells and lead to malignant transformation (87).

There is a growing body of evidence and an increasing 
number of investigators who believe that inhibition of CRC by NSAIDs does not occur necessarily via the inhibition of proliferation by downregulating PG synthesis. Moreover, it was found that NSAIDs inhibit cell proliferation in colon cancer cells that do not express COX enzymes or produce PGs (93-99). Finally, recent studies indicate that growth is inhibited by these drugs due to the induction of apoptosis (programmed cell death) (72-80,90-102).

Apoptosis is a strictly regulated form of cell death that is distinct from necrosis (103). Morphologically, it is characterized by nuclear fragmentation, chromatin condensation, cell shrinkage, loss of cell surface features and detachment of the cell from the basement membrane. As the process continues, the cell separates into several membrane-bound fragments known as apoptotic bodies.

Pasricha et al (101) were the first to describe the in vivo effects of sulindac-induced apoptosis. This was confirmed by animal studies showing increased levels of apoptosis in carcinogen-treated rats and Min mice after sulindac therapy. The mechanisms by which sulindac affects apoptosis are not clear. It seems to be independent of the expression of $b c l-2$, bax or $p 53$ pathways, or alterations in levels of PG $(94,95)$. Possible mechanisms include intervention in the AA metabolisms by COX-2 inhibition, downregulation of the betacatenin oncogenic pathway and upregulation of the expression of bak, a proapoptotic family member of bcl-2 (89).

Chan et al (77) showed that, by inhibiting COX enzymes, NSAIDs cause a buildup of the COX substrate, AA, that activates the production of ceramide, a strong apoptosis inducer.

Substantial data indicate that the most important biological mechanism involves a combination of inhibition of proliferation and induction of apoptosis. It has been suggested that NSAIDs inhibit proliferation by downregulating the expression of cyclin D1 protein, inhibiting $\mathrm{CDK}_{4}$ kinase activity and increasing cell destruction by upregulating proapoptosis genes such as bak (89).

COX enzymes, and in particular COX-2, are known to metabolize many procarcinogens by their peroxidase activity or through the peroxyl radicals generated during AA oxygenation (104). The substrate activity includes, among others, aflatoxins, hydroperoxides, halogenated pesticides, amines, phenols and polycyclichydrocarbons (72).

NSAIDs may also restore impaired immune response. $\mathrm{PGE}_{2}$ reduces the expression of human leukocyte I and II antigens. The expression of these antigens is reduced in colonic tumours, as well as in normal adjacent mucosa $(72,105,106)$. $\mathrm{PGE}_{2}$ also suppresses $\mathrm{T}$ cell proliferation, lymphokine production, macrophage activation and T cell-mediated cytotoxicity $(39,72,79,87)$. Therefore, NSAID treatment can indirectly augment immune surveillance.

Other possible mechanisms include interference with $G$ protein signal transduction and the transmembrane calcium influx, inhibition of other enzymes, such as phosphodiesterase, folate-dependent enzymes and cyclic AMP. It has also been suggested that NSAIDs induce terminal differen- tiation, inhibit angiogenesis, suppress cell replication and scavenge reactive oxygen radicals $(39,72,79,87)$.

\section{SPECIFIC INHIBITION OF COX-2}

The new COX-2 specific inhibitors, the super-ASAs, are commercially available. They offer all the well known benefits of ASA or NSAID, ie, relief of pain, fever and inflammation, without gastric toxicity.

The use of selective COX-2 inhibitors as chemopreventive agents is being actively investigated. Data from several studies suggest that inhibition of PG synthesis, particularly through inhibition of COX-2, can be chemopreventive $(86,88,107)$. Upregulation of COX-2 expression occurs in $40 \%$ to $50 \%$ of CRP and up to $85 \%$ of CRC (82-88). Tsujii and DuBois (108) showed that COX-2 overexpression in an intestinal epithelial cell line (rat intestinal epithelial-1 cells) blunted the apoptotic effects of sulindac sulphide. Sheng et al (93) demonstrated that a selective inhibition of COX-2 inhibited colon cancer cell growth, and Reddy's group (109) reported that a specific COX-2 inhibitor (SC58635) had chemopreventive activity in the rat aberrant crypt focus model induced by azoxymethane. A group from Japan (97) showed that nimesulide, a selective COX-2 inhibitor that is commercially available in some European countries and Japan, significantly diminished the number and size of polyps in azoxymethane animal models. These models may be particularly relevant for the chemoprevention of sporadic CRC because aberrant crypt foci are recognized as early preneoplastic lesions in the colonic mucosa of patients with CRC. Their results might be noteworthy because the degree of inhibition of colon carcinogenesis exceeded that seen with other commonly used NSAIDs (109). Moreover, long term administration of celecoxib at 1500 ppm did not induce any toxic side effects. The same group has also shown that an increased expression of COX-2 is an early event in the sequence of polyp formation (110) and that celecoxib inhibits the initiation as well as promotion and progression phases of CRC carcinogenesis $(109,110)$. Oshima et al (96) crossed COX-2 knockout mice with APC mutant Min mice and demonstrated a marked reduction in the number of intestinal adenomas. This study directly demonstrates that regulation of COX-2 appears to affect colonic carcinogenesis.

The use of selective COX-2 inhibitors as chemopreventive agents is being actively investigated. Searle-Monsanto (Arber, personal communication) has completed a doubleblind, placebo controlled trial of their new selective COX-2 inhibitor, celecoxib (Celebrex), in subjects with FAP with intact colons. Eighty-one patients from London, United Kingdom (St Marks Hospital) and Texas (MD Anderson Medical Center) were randomly selected to receive two doses of the drug or a placebo for six months. In 1999, Searle Monsanto launched an international, multicentre study to evaluate the efficacy of their new specific COX-2 inhibitor (Celecoxib) in preventing the recurrence of sporadic CRP (Arber, personal communication). Merck Sharp \& Dohme 
(Rahway, New Jersey) will also study its COX-2 inhibitor (Rofecoxib) in a similar trial starting this year.

\section{COX-2 IS NOT THE ENTIRE STORY}

It seems likely that inhibition of PG synthesis is only one of several biochemical target for NSAIDs action. When considering the chemopreventive action of specific COX-2 inhibitors, one should keep in mind that $50 \%$ to $60 \%$ of CRP and $15 \%$ of CRC do not express this enzyme. From cell culture and animal models, it is clear that NSAIDs are chemopreventive without the need to inhibit COX-2. Several lines of evidence suggest that there are biochemical targets other than COX-2 that mediate the chemopreventive activity of NSAID-type drugs. The potency of NSAIDs to inhibit growth and/or to induce apoptosis does not correlate well with their potency as inhibitors of PG synthesis $(64,94,95,99)$. The lack of COX-2 expression in normal intestinal mucosa and its overexpression in colonic neoplasia is a tidy explanation for a selective action of COX-2 inhibitors on neoplastic colon mucosa, without major biological effects on the normal colonic mucosa or the risk of gastrodoudenal ulcers.

Sulindac is a prodrug (a sulphoxide) that rapidly metabolizes in colonocytes and hepatocytes $(94,95,99)$. About half of the sulphoxide is initially converted by a reversible oxidation/reduction reaction to sulindac sulphide, which is a potent anti-inflammatory drug (an NSAID) that inhibits PG synthesis by inhibiting both COX-1 and COX-2. The other half of the sulphoxide is inversely reduced to a sulphone metabolite. Sulindac sulphone is not an NSAID because it lacks anti-inflammatory properties and does not inhibit COX-1 or COX-2 proteins $(94,95)$. Due to the reversibility of the sulphide reaction, the sulphone is ultimately the major sulindac metabolite. Others and ourselves $(74-76,89-95,100)$ have shown that both sulindac metabolites inhibit the growth of a variety of cancer cell lines. In these studies, the major mechanism responsible for the growth inhibition was induction of apoptosis. Pasricha et al (101) reported that the basal apoptotic rate in adenomas from FAP patients is significantly lower than that observed in sporadic adenomas and that sulindac treatment increases the apoptotic rate threefold without affecting the rate of proliferation. Similar preliminary results were obtained in a clinical trial in FAP subjects using sulindac sulphone $(99,111)$.

Sulindac sulphone, as an inhibitor of PG synthesis in vitro or in the rat colon, (99), is at least 5000-fold less potent than the sulphide metabolite; however, it prevents carcinogen-induced cancers in the azoxymethane rat colon cancer model (99). Hanif et al (102) showed that NSAIDs induce apoptosis in HCT-15 cells, a cell line that lacks COX transcripts and does not produce PG. Furthermore, addition of PG does not prevent growth inhibition or induction of apoptosis by sulindac metabolites (102). A preliminary report of a phase II clinical trial of sulindac sulphone in human subjects with FAP has suggested that the drug causes regression of colonic adenomas (111). In May 1999, during the annual meeting of the American Association of Gastroenterol- ogy, Orlando, Florida, Piazza et al (112) revealed a novel mechanism explaining the antineoplastic properties of sulindac sulphone. This molecule inhibits tumour growth by inhibiting the activity of cyclic GMP phosphodiesterase in neoplastic tissue only.

\section{SUMMARY}

Perhaps the most important consequence of Waddell and Loughry's (16) sentinel observations has been that sulindac caused adenomatous polyp regression in FAP patients. It established a model for the investigation of the biological and biochemical mechanisms of chemoprevention using a class of agents that have demonstrable activity in human neoplastic tissue. The mechanisms of cancer chemoprevention have only just begun to unravel, and there is much more to come. It is likely that more effective chemopreventive agents will be designed based on these new discoveries. The challenge is to find the proper place for chemoprevention in the overall effort toward cancer prevention, not only in subjects at risk for colon cancer but also those at risk for other cancers.

Taken together, current evidence strongly indicates that the NSAID class of drugs can inhibit the process of colonic carcinogenesis. The prospective studies conducted since the report was published by the American Cancer Society (55) strongly support the notion and confirm the data that NSAIDs prevent the development and/or promotion of CRC. In the event that intervention trials successfully establish the causality of the NSAID/CRC relationship, then it will be possible to determine the most effective and safe method and duration of NSAID use for optimal protection. For the time being, the standard care for patients with CRP is still polypectomy and not therapy with NSAIDs.

Whether there is one, two or more biochemical targets for the chemopreventive effects of NSAIDs and their nonNSAID metabolites is yet to be determined. The presence of multiple potential biochemical targets is potentially very good news because it is possible that potent inhibitors of both targets may be more effective than either agent alone. One or more of the NSAID targets may have an even greater role to play in cancer sites that are less amenable than CRC is to prevention, screening and surveillance programs.

There is no need for further placebo trials. However, several unresolved issues need to be addressed before a definite recommendation can be made for the widespread use of NSAIDs to prevent CRC. What is the ultimate drug? What is the optimal dose? What is the optimal age? What is the target population for chemoprevention trials?

ACKNOWLEDGEMENTS: The author is grateful to Mrs. Limor Baron for excellent secretarial work.

\section{REFERENCES}

1. Vane JR, Flower RJ, Botting RM. History of aspirin and its mechanism of action. Stroke 1990:21(12 Suppl):IV12-23.

2. Vainio H, Morgan G. Aspirin for the second hundred years: new users for an old drug. Pharmacol Toxicol 1997;81:151-2.

3. Cole P, Sateren W. The evolving picture of cancer in America. J Natl Cancer Inst 1995;87:159-60. 
4. Parkin DM, Pisani P, Ferlay J. Global cancer statistics. CA Cancer J Clin 1999:49:33-64

5. Parker SL, Tong T, Bolden S, Wingo PA. Cancer statistics, 1996. CA Cancer J Clin 1996;46:5-27.

6. Morson B. President's address. The polyp-cancer sequence in the large bowel. Proc R Soc Mes 1974;67:451-7.

7. Fearon ER, Vogelstein B. A genetic model for colorectal tumorigenesis. Cell 1990;61:759-67.

8. Hamilton SR. The molecular genetics of colorectal neoplasia. Gastroenterology 1993;105:3-7.

9. Winawer SJ, Zauber AG, O'Brien MJ, et al. Randomized comparison of surveillance intervals after colonoscopic removal of newly diagnosed adenomatous polyps. N Engl J Med 1993;328:901-6.

10. Kelloff G. Chemoprevention of colorectal. In: Young G, Rozen P, Levin B, eds. Prevention and Early Detection of Colorectal Cancer. Philadelphia: WB Saunders, 1996:116-39.

11. Reddy BS, Naylini J, Tokumo K, Rigotty J, Zang E, Kelloff G. Chemoprevention of colon carcinogenesis by concurrent administration of piroxicam, a nonsteroidal anti-inflammatory drug with D,L-alpha-difluoromnthylornithine, an ornithine decarboxylase inhibitor, in diet. Cancer Res 1990;50:2562-8.

12. Craven PA, DeRuberits FR. Effects of aspirin on 1,2-dimethylhydrazineinduced colonic carcinogenesis. Carcinogenesis 1992;13:541-6.

13. Reddy BS, Rao CV, Rivenson A, Kelloff G. Inhibitory effect of aspirin on azoxymethance-induced colon carcinogenesis in F344 rates. Carcinogenesis 1993;14:1493-7.

14. Reddy BS, Tokumo K, Kulkarni N, Aligia C, Kelloff G. Inhibition of colon carcinogenesis by prostaglandin synthesis inhibitors and related compounds. Carcinogenesis 1992;13:1019-23.

15. Rao CV, Rivenson AJ, Simi B, et al. Chemoprevention of colon carcinogenesis by sulindac, a nonsteroidal anti-inflammatory agent. Cancer Res 1995;55:1464-72.

16. Waddell WR, Loughry RW. Sulindac for polyposis of the colon. J Surg Oncol 1983;24:83-7.

17. Waddell WR, Ganser GF Cerise EJ, Loughry RW. Sulindac for polyposis of colon. Am J Surg 1989;157:175-9.

18. Rigau J, Pique JM, Rubio E, Planas R, Tarrech JM, Bordas JM. Effects of long-term sulindac therapy on colonic polyposis. Ann Intern Med 1991;115:952-4.

19. Labayle D, Fischer D, Vielh P, et al. Sulindac causes regression of rectal polyps in familial adenomatous polyposis. Gastroenterology 1991;101:635-9.

20. Giardiello FM, Hamilton SR, Krush AJ, et al. Treatment of colonic and rectal adenomas with sulindac in fmilial adenomatous polyposis. N Engl J Med 1993;328:1313-6.

21. Marnette LJ. Aspirin and the potential role of prostaglandins in colon cancer. Cancer Res 1992;52:5575-89.

22. Vainio H, Morgan G, Kleihues P. An international evaluation of the cancer preventive potential of nonsteroidal anti-inflammatory drugs. Cancer Epidemiol Biomarkers Prev 1997;6:749-53.

23. Thun MJ. NSAIDs use and decrease risk of gastrointestinal cancers. Gastroenterol Clin North Am 1996;25:333-47.

24. DuBois RN, Giardiello FM, Smalley WE. Nonsteroidal anti-inflammatory drugs, eicosanoids, and colorectal cancer prevention. Gastroenterol Clin North Am 1996;25:773-91.

25. Thun MJ. Aspirin and gastrointestinal cancer. Adv Exp Med Biol 1997:400A:395-402.

26. Waddell WR, Gerner RE. Indomethacin and ascorbate inhibit desmoid tumors. J Surg Oncol 1980;15:85-90.

27. Kudo T, Narisawa T, Abo S. Antitumor activity of indomethacin on methylazoxymethanol - induced large bowel tumors in rats. Gann 1980:71:260-4.

28. Takeo MT. Cyclooxygenase-2 inhibitors in tomorigenesis (Part II). Natl Cancer Inst 1998;90:1609-20.

29. Levy GN. Prostaglandin H synthases, nonsteroidal anti-inflamatory drugs, and colon cancer. FASEB J 1997;11:234-47.

30. Reddy BS, Maruyama H, Kelliff G. Dose-related inhibition of colon carcinogenesis by dietary piroxicam, a nonsteroidal anti-inflammatory drug, during different stages of rat colon tumor development. Cancer Res 1987;47:5340-6.

31. Wargovich MJ, Chen CD, Harris C, Yang E, Velasco M. Inhibition of aberrant crypt growth by non-steroidal anti-inflammatory agents and differentiation agents in the colon. Int J Cancer 1995;60:515-9.

32. Beazer-Barclay Y, Levy DB, Moser AR, et al. Sulindac suppresses tumorigenesis in the Min mouse. Carcinogenesis 1996;17:1757-60.

33. Moser AR, Pitot HC, Dove WF. A dominant mutation that predisposes to multiple intestinal neoplasia in the mouse. Science 1990;247:322-5.

34. Oshima M, Oshima H, Kitagawa K. Loss of APC heterozygosity and abnormal tissue building in nascent intestinal polyps in mice carrying a truncated APC gene. Proc Natl Acad Sci USA 1995;92:4482-6.

35. Giardiello FM. NSAIDs-induced polyp regression in familial adenomatous polyposis patients. Gastroenterol Clin North Am 1996;25:349-61.

36. Nuegent KP, Farmer KC, Spigelman AD, Williams CB, Phillips RK. Randomized controlled trial of the effect of sulindac on doudenal and rectal polyposis and cell proliferation in patients with familial adenomatous polyposis. Br J Surg 1993;80:1618-9.

37. Parker AL, Kadakia SC, Maccini DM, et al. Disappearance of duodenal polyps in Gardner's syndrome with sulindac therapy. Am J Gastroenterol 1993;88:93-4.

38. Spagnesi TM, Tonelli F, Dolara P, et al. Rectal proliferation and polyp occurrence in patients with familial adenomatous polyposis after sulindac treatment. Gastroenterology 1994;106:362-6.

39. Luk GD. Prevention of gastrointestinal cancer - the potential role of NSAIDs in colorectal cancer. Schweiz Med Wochenschr 1996;126:801-12.

40. Marnette LJ. Aspirin and related nonsteroidal anti-inflammatory drugs as chemopreventive agents against colon cancer. Prev Med 1995;24:103-6.

41. Gann PH, Manson JE, Glunn RJ, Hennekens CH. Low dose aspirin and incidence of colorectal tumors in randomized trial. J Natl Cancer Inst 1993;85:1220-4.

42. Stumer T, Glynn RJ, Lee IM, et al. Aspirin use and colorectal cancer: Post trial follow-up data from the Physicians Health Study. Ann Intern Med 1998;128:713-20.

43. Paganini-Hill A, Chao A, Ross RK, Henderson BE. Aspirin use and chronic disease: A cohort study of the elderly. BMJ 1989;299:247-50.

44. Paganini-Hill A. Aspirin and colorectal cancer: The Leisure World cohort revisited. Prev Med 1995;24:113-5.

45. Smalley W, Ray WA, Daugherty J, Griffin MR. Use of nonsteroidal anti-inflammatory drugs and incidence of colorectal cancer. Arch Intern Med 1999;159:161-6.

46. Kune GA, Kune S, Watson LF. Colorectal cancer risk, chronic illnesses, operations, and medications: case control result from the Melbourne Colorectal Cancer Study. Cancer Res 1988:48:4399-404.

47. Muscat JE, Wynder EL. Anti-inflammatory drugs and rheumatoid arthritis. J Natl Cancer Inst 1993;85:921-2.

48. Peleg II, Lubin MF, Cotsonis GA, Clarck WS, Wilcox CM. Long-term use of nonsteroidal anti-inflammatory drugs and other chemopreventors and risk of subsequent colorectal neoplasia. Dig Dis Sci 1996;41:1319-26.

49. Reeves MJ, Newcomb PA, Trentham-Dietz A, Storer BE, Remington PL. Nonsteroidal anti-inflammatory drug use and protection against colorectal cancer in women. Cancer Epidemiol Biomarkers Prev 1996;5:955-60.

50. Suh O, Mettlin C, Petrelli NJ. Aspirin use, cancer, and polyps of the large bowel. Cancer 1993;72:1171-7.

51. Rosenberg L, Palmer RJ, Zauber AG, Warshauer ME, Stolley PD, Shapiro S. A hypothesis: nonsteroidal anti-inflammatory drugs reduce the incidence of large-bowel cancer. J Natl Cancer Inst 1991,83:355-8.

52. Muller AD, Sonnenberg A, Wasserman IH. Disease preceding colon cancer. A case-control study among veterans. Dig Dig Sci, 1994;39:2480-4.

53. Peleg II, Maibach HT, Brown SH, Wilcox CM. Aspirin and nonsteroidal anti-inflammatory drug use and the risk of subsequent colorectal cancer. Arch Intern Med 1994;154:394-9.

54. Muscat JE, Stellman SD, Wynder EL. Nonsteroidal anti-inflammatory drugs and colorectal cancer. Cancer 1994;74:1847-54.

55. Thun MJ, Namboodiri MM, Heath CW. Aspirin use and reduced risk of fatal colon cancer. N Engl J Med 1991;325:1593-6.

56. Giovanucci E, Egan KM, Hunter DJ, et al. Aspirin and the risk of colorectal cancer in women. N Engl J Med 1995;333:609-14.

57. Rosenberg L, Louick C, Shapiro S. Nonsteroidal anti-inflammatory drug use and reduced risk of large bowel carcinoma. Cancer 1998;82:3326-33.

58. Giovannucci E, Rimm EB, Stampfer MJ, Colditz GA, Ascherio A, Willett WC. Aspirin use and the risk for colorectal cancer and adenoma in male health professionals. Ann Intern Med 1994;121:241-6.

59. Schreinemachers DM, Everson RB. Aspirin use and lung, colon and breast cancer incidence in a prospective study. Epidemiology 1994;5:138-46.

60. Cibere J, Sibley J, Haga M. Rheumatoid arthiritis and the risk of malignancy. Arthritis Rheum 1997;40:1580-6.

61. Kauppi M, Pukkala E, Isomaki H. Low incidence of colorectal cancer in patients with rheumatoid arthritis. Clin Exp Rheumatol 1996:14:551-3.

62. Girdley G, McLaughlin JK, Ekbom A, et al. Incidence of cancer among patients with arthritis. J Natl Cancer Inst 1993;85:307-11.

63. Breuer-Katschinski B, Nemes K, Rump B, et al. The colorectal adenoma study group. Long-term use of nonsteroidal anti-inflammatory drugs and the risk of colorectal adenomas. Digestion 2000;61:129-134. 
64. Martinez ME, McPherson RS, Levin B, Annegers JF. Aspirin and other nonsteroidal anti-inflammatory drugs and risk of colorectal adenomatous polyps among endoscoped individuals. Cancer Epidemiol Biomarkers Prev 1995;4:703-7.

65. Sandler RS, Calanko JC, Murry SC, Helam JF, Woosley JT. Aspirin and nonsteroidal anti-inflammatory agents and risk for colorectal adenomas. Gastroenterology 1998;114:441-7.

66. Logan RF, Little J, Hawltin PG, Hardcastle JD. Effect of aspirin and nonsteroidal anti-inflammatory drugs on colorectal adenomas: case control study of subjects participating in the Nottingham faecal occult blood screening programme. BMJ 1993;307:285-9.

67. Greenberg ER, Baron JA, Freeman DHJ, Mandel JS, Haile R. Reduced risk of large-bowel adenomas among aspirin users: The Polyp Prevention Study Group. J Natl Cancer Inst 1993;85:912-6.

68. Landenheim J, Garcia G, Titzer D, et al. Effect of sulindac on sporadic colonic polyps. Gastroenterology 1995;108:1083-7.

69. Hixson LJ, Earnest DL, Fennerty MB, Sampliner RE. NSAID effect on sporadic colon polyps. Am J Gastoenterol 1993;88:1652-6.

70. Disario JA, Alberts ES, Tietze CC, et al. Sulindac induces regression and prevents progression of sporadic colorectal adenomas. Gastroenterology 1997:112:A555. (Abst)

71. DuBois RN. Nonsteroidal anti-inflammatory drugs use and sopradic colorectal adenomas. Gastroenterology 1995;108:1310-4.

72. Shiff SJ, Rigas B. Nonsteroidal anti-inflamatory drugs and colorectal cancer: evolving concepts of their chemopreventive actions. Gastroenterology 1997;113:1992-8.

73. Bannett A, Del Tacca M. Prostaglandins and human colon carcinoma. Gut 1975;16:409.

74. Hixson LJ, Alberts DS, Krutzsch M, et al. Anti-proliferative effect on nonsteroidal anti-inflammatory drugs against human colon cancer cells. Cancer Epidemiol Biomarkers Prev 1994:3:433-8.

75. Alberts DS, Hixson LJ, Ahnen D, et al. Do NSAIDs exert their colon chemoprevention activities through the inhibition of mucosal prostaglandin synthesis. J Cell Biochem 1995;22:18-23.

76. Shiff SJ, Qiao L, Tsai L-L, Rigas B. Sulindac suldide, an aspirin like compound, inhibits proliferation, causes cell cycle quiescence, and induces apoptosis in HT-29 colon adenocarcinoma cells. J Clin Invest 1995;96:491-503.

77. Chan TA, Morin PJ, Vogelstein B, Kinzler KW. Mechanisms underlying nonsteroidal anti-inflammatory drug mediated apoptosis. Proc Natl Acad Sci USA 1998;95:681-6.

78. Williams CS, Smalley W, DuBois RN. Aspirin use and potential mechanisms for colorectal cancer prevention. J Clin Invest 1997;100:1325-9.

79. Ahnen DJ. Colon cancer prevention by NSAIDs: What is the mechanism of action? Eur J Surg Suppl 1998;582:111-4.

80. Taketo MM. Cyclooxygenase-2 inhibitors in tumorigenesis (Part I). Natl Cancer Inst 1998;90:1529-36.

81. Duggan DE, Hooke KF, Hwang SS. Kinetics of the tissue distributions of sulindac and metabolites: relevance to sites and rates of bioactivation. Drug Metab Dispos 1980;8:241-6.

82. Meade EA, Smith WL, DeWitt DL. Differential inhibition of prostaglandin endoperoxidase synthase (cyclooxygenase) isozymes by aspirin and other non-steroidal anti-inflammatory drugs. J Biol Chem 1993;268:6610-4.

83. Eberhart CE, Dubois RN. Eicosanoids and the gastrointestinal tract. Gastroenterology 1995;109:285-301.

84. Kargman SL, O'Neill GP, Vickers PJ, Evans JF, Mancini JA, Jothy S. Expression of prostaglandin $\mathrm{G} / \mathrm{H}$ synthase- 1 and -2 protein in human colon cancer. Cancer Res 1995;55:2556-9.

85. Heath CW, Thun MJ, Greenberg ER, Levin B, Marnett LJ. Nonsteroidal anti-inflammatory drugs and human cancer. Cancer 1994;74:2885-8.

86. Eberhart CE, Coffey RJ, Radhika A, Giardiello FM, Ferrenbach S, DuBois RN. Up-regulation of cyclooxygenase 2 gene expression in human colorectal and adenocarcinomas. Gastroenterology 1994;107:1183-8.

87. Garay CA, Engstrom PF. Chemoprevention of colorectal cancer: dietary and pharmacologic approaches. Oncology (Huntingt) 1999;13:89-97.

88. Sano H, Kawahito Y, Wilder RL, et al. Expression of cyclooxygenase-1 and-2 human colorectal cancer. Cancer Res 1995;55:3685-9.

89. Arber N, Han E.K-H, Sgambato A, et al. Transformation of rat enterocytes by a c-K-ras oncogene increases resistance to growth inhibition and apoptosis induced by sulindac sulfide. Gastroenterology 1997;113:1892-900.

90. Goldberg Y, Nassif II, Pittas A, et al. The anti-proliferative effect of sulindac and sulindac sulfide on HT-29 colon cancer cells: alterations in tumor suppressor and cell cycle-regulatory proteins. Oncogene 1996;12:893-901.

91. Shiff SJ, Koutsos MI, Quiao L, Rigas B. Nonsteroidal anti-inflammatory drugs inhibit the proliferation of colon adenocarcinoma cells: effects on cell cycle and apoptosis. Exp Cell Res 1996;222:179-188.

92. Piazza G, Rahm ALK, Pamukcu R, Ahnen DJ. Induction of apoptosis by sulindac metabolites involves a $p 53$ and bcl-2 independent mechanism and does not require cell cycle arrest. Gastroenterology 1996;110:577A. (Abst)

93. Sheng H, Shao J, Kirkland SC, et al. Inhibition of human colon cancer cell growth by selective inhibition of cyclooxygenase-2. J Clin Invest 1997;99:2254-9.

94. Piazza GA, Kulchak Rabm AL, Krutzsch M, et al. Antineoplastic drugs sulindac sulfide and sulfone inhibit cell growth by inducing apoptosis. Cancer Res 1995;55:3110-6.

95. Piazza GA, Rahm AK, Finn B, Stoumen AL, Pamukcu R, Ahnen DJ. Apoptosis fully accounts for the growth inhibitory properties of sulindac metabolites by a mechanism independent of cyclooxygenase inhibition, cell cycle arrest or $p 53$ mediation. Cancer Res 1997;57:2452-9.

96. Oshima M, Dinchuk JE, Kargman SL, et al. Suppression of intestinal polyposis in APC knockout mice by inhibition of cyclooxygenase 2 (COX-2). Cell 1996;87:803-9.

97. Fukutake M, Nakatsugi S, Isoi T, et al. Suppressive effects of nimesulide, a selective inhibitor of cyclooxygenase-2, on azoxymthane-induced colon carcinogenesis in mice. Carcinogenesis 1998;19:1939-42.

98. Hale AJ, Smith CA, Sutherland LC, et al. Apoptosis: molecular regulation of cell death. Eur J Biochem 1996;236:1-26.

99. Piazza GA, Fryer BJ, van Stolk RU, et al. Selective apoptosis of neoplastic cells accompanies polyp regression in familial adenomatous polyposis (FAP) patients treated with FGN-1 (sulindac sulfone): evidence for a cyclooxygenase independent mechanism. Gastroenterology 1997;112:A638.

100. Qiao L, Shiff SJ, Rigas B. Sulindac sulfide inhibits the proliferation of colon cancer cells: diminished expression of the proliferation markers PCNA and ki-67. Cancer Lett 1997;115:229-34.

101. Pasricha PJ, Bedi A, O'Connor K, et al. The effects of sulindac on colorectal proliferation and apoptosis in familial adenomatous polyposis. Gastroenterology 1995;109:994-8.

102. Hanif R, Pittas A, Feng Y, et al. Effects of nonsteroidal antiinflammatory drugs on proliferation and on induction of apoptosis in colon cancer cells by a prostaglandin-independent pathway. Biochem Pharmacol 1996;52:237-45.

103. Hale AJ, Smith CA, Sutherland LC, et al. Apoptosis: molecular regulation of cell death. Eur J Biochem 1996;236:1-26.

104. DuBois RN, Shao J, Tsujii M, Sheng H, Beauchamp RD. GI delay in cells overexpressing prostaglandin endoperoxide synthase-2. Cancer Res 1996;56:733-7.

105. Tsioulias G, Godwin TA, Goldstein MF, et al. Loss of colonic HLA antigens in familial adenomatous polyposis. Cancer Res 1992;52:3449-52.

106. Tsioulias GJ, Triadafilopoulos G, Goldin E, et al. Expression of HLA class I antigens in sporadic adenomas and histologically normal mucosa of the colon. Cancer Res 1993;53:2374-8.

107. Kargman SL, O'Neill GP, Vickers PJ, Evans JF, Mancini JA, Jothy S. Expression of prostaglandin $\mathrm{G} / \mathrm{H}$ synthase -1 and -2 protein in human colon cancer. Cancer Res 1995;55:2556-9.

108. Tsujii M, DuBois RN. Alterations in cellular adhesion and apoptosis in epithelial cells overexpressing prostaglandin endoperoxide synthase 2. Cell 1994;84:493-501.

109. Reddy BS, Rao CV, Seibert K. Evaluation of cyclooxygenase-2 inhibitor for potential chemopreventive properties in colon carcinogenesis. Cancer Res 1996;56:4566-71.

110. Singh J, Hamid R, Reddy BS. Dietary fat and colon cancer: modulation of cyclooxygenase- 2 by types and amount of dietary fat during the postinitation stage of colon carcinogenesis. Cancer Res 1997;57:3465-70.

111. van Stolk RU, DeYoung B, Church JM, et al. Clinco-pathologic correlation of rectal adenoma in patients with familial adenomatous polypsosis (FAP) treated with sulindac sulfone in a phase I $\backslash$ II trial. Gastroenterology 1997;112:A673. (Abst)

112. Piazza GA, Li H, Liu L, et al. Cyclic GMP (CG) phosphodiesterase (PDE) inhibition: A novel mechanism for the antineoplastic properties of exisulind. Gastroenterology 1999;116:A485. (Abst) 


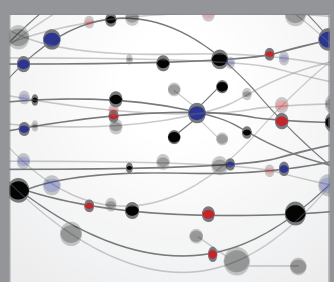

The Scientific World Journal
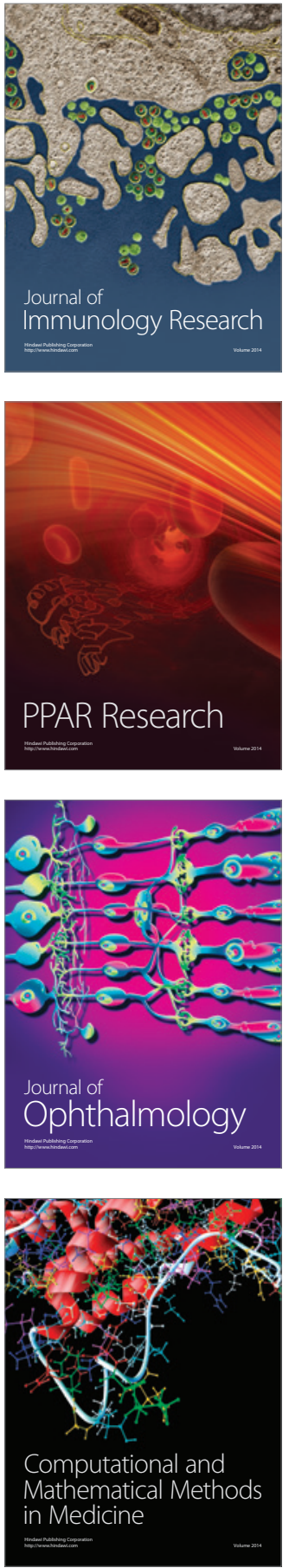

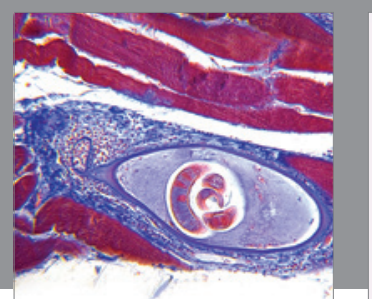

Gastroenterology Research and Practice

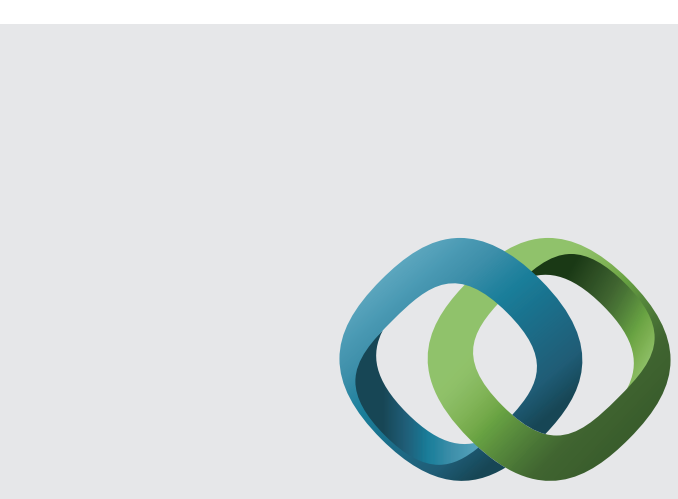

\section{Hindawi}

Submit your manuscripts at

http://www.hindawi.com
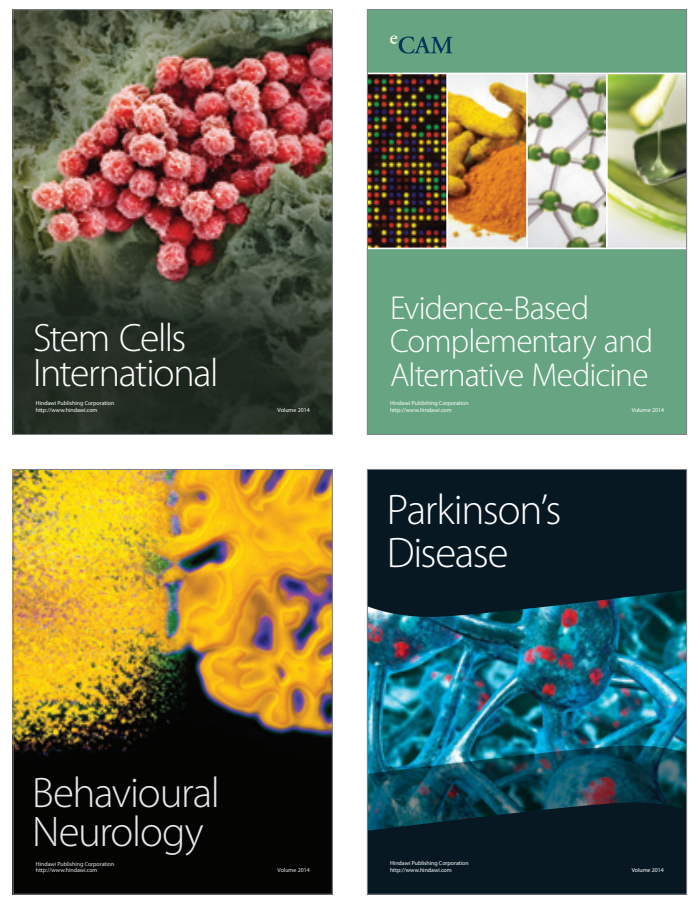
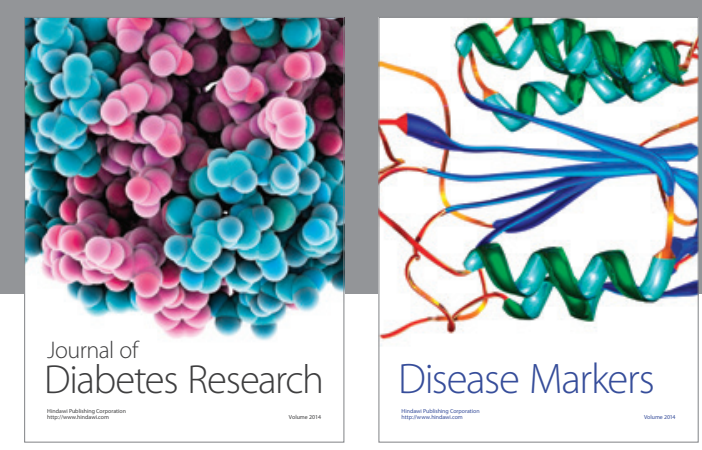

Disease Markers
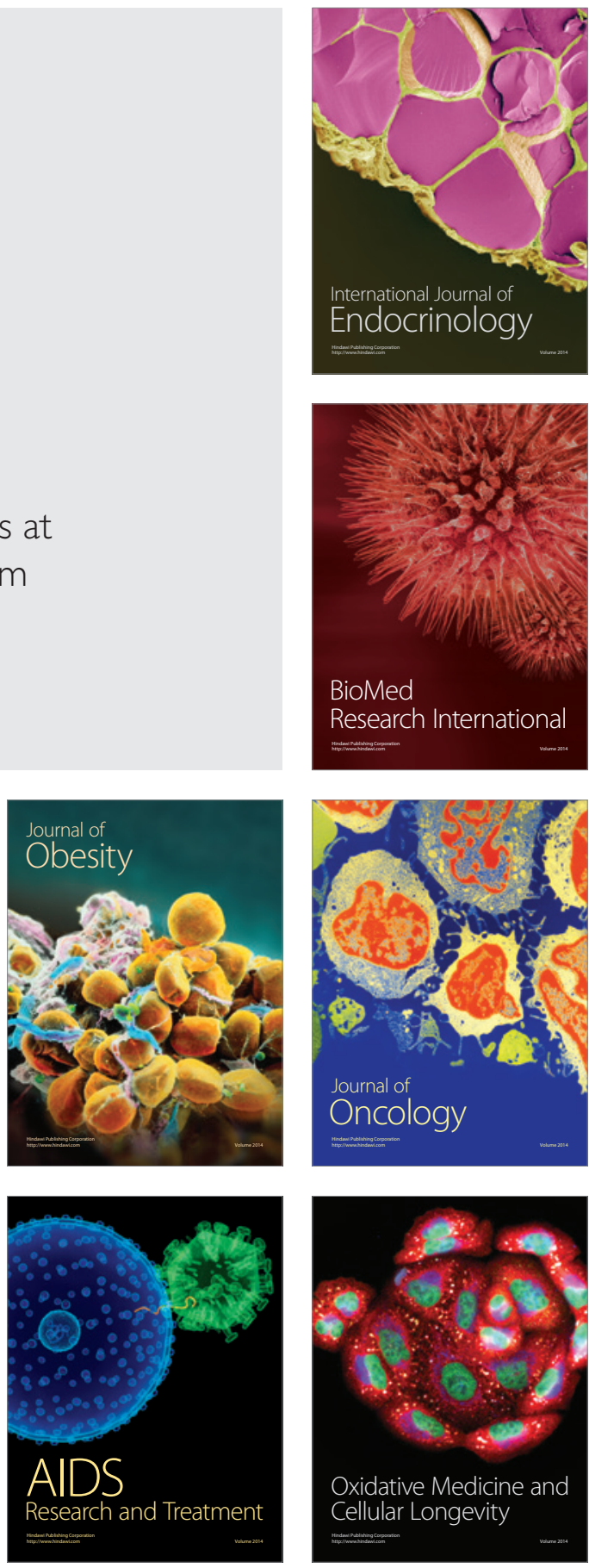